\title{
THE ELECTRIC VEHICLE ROUTING OPTIMIZING ALGORITHM AND THE CHARGING STATIONS' LAYOUT ANALYSIS IN BEIJING
}

\author{
Lu, X. C.; Chen, Q. B. \& Zhang, Z. J. \\ School of Economics \& Management, Beijing Jiaotong University, Beijing, China \\ E-Mail: zhjzhang@bjtu.edu.cn
}

\begin{abstract}
With the development of economy, energy dilemma and environment protection give urgent pressure on automobile industry. More and more countries are making new energy vehicle policy. How to choose a proper routing when driving an electric vehicle? Does charging stations layout in a city meet the demand of electric vehicles? This paper gives out the electric vehicles' routing optimizing algorithm. The algorithm focus on decision policy before an electric vehicle starts. There are 3 kinds of situations: the situation moving to destination, moving to a charging station and staying origin. Each situation has its judgment and it is discussed in detail. Except that, the electric vehicles' routing optimization is solved in this paper. By applying routing optimizing algorithm, a multi-agent simulation model is build and the model is running with real data of charging stations in Beijing. The simulation results show that this model is valid. Through analysis of simulation data, this paper concludes that the layout of charging stations in Beijing is not reasonable, because charging stations are not visited by electric vehicles equally. 4 charging stations have higher visiting frequency. More charging stations should be built near these areas.

(Received, processed and accepted by the Chinese Representative Office.)
\end{abstract}

Key Words: Electric Vehicles' Routing Optimizing, Multi-agent Simulation Model, Charging Stations Layout

\section{INTRODUCTION}

With the rapid development of the economy in China, the life standard of people is being continuously improved and the demand of owning automobile has also increased dramatically. However, the problem of resources and environment in China restricts the development of cars that run on fossil fuels. To develop electric vehicles has become an effective method to solve this problem. To promote the development of electric vehicles, China and local governments have issued series of guidelines and policies which encourage the development of electric vehicles. In the meantime, the research about electric vehicles has become a hot spot in academic circles. Battery charging is a key problem in the development of electric vehicles. The layout of charging stations will affect the electric vehicles application. In China, a set of mature theory in charging stations' planning and construction have not been formed. However, the charging stations already have been setup in many cities, such as Beijing. So we must speed up the research of charging stations' layout in order to meet this situation. There have been 13 charging stations in Beijing now. No one knows the layout of these charging stations is reasonable or not. How to plan its routing before an electric vehicle moving to a destination? This paper will research these questions.

\section{LITERATURE REVIEW}

Electric vehicles are increasing rapidly in China. For example, China has contributed $23 \%$ and $44 \%$ of the total NEV (New Energy Vehicle) production in 2010 and 2011 [1, 2]. 
More and more studies begin to focus on the problems of electric vehicles and charging stations layout. Raviv studied the problem of scheduling the charging process in a battery swich station with the objective of optimizing a weighted measure of service level and cost [3]. Hiwatari et al. developed a road traffic simulator and proposed a search algorithm for the effective layout of charging stations based on the location of electric vehicles running out of electricity by the road traffic simulator [4].

Yao et al. discussed the urgent to develop low-carbon vehicles in China [5]. Zhou et al. discussed the electric vehicle charging stations operation mode in China [6]. They gave a conclusion that charging stations will operate mainly depending on battery replacing mode in China.

Yilmaz and Krein reviewed the current status and implementation of battery chargers, charging power levels, and infrastructure for plug-in electric vehicles and hybrids [7]. They summered that the availability of charging infrastructure reduces on-board energy storage requirements and costs.

Guo put forward some unreasonable phenomena in electric vehicles industry in China [8]. He pointed out that the development of small high-efficiency electric vehicles is the strategic choice for vehicle industry. He also gave electric vehicles development routing in his paper.

Liu established an evaluation model of impact of charging stations distribution in Beijing on power grid [9]. This paper pointed out that the smaller the charging station service scope is, the smaller the charging station interference on the power grid is. And now Beijing power grid capacity can withstand the influences of charging stations. Liu developed a two-step screening method based on geographical factors and service radius to locate charging stations [10]. Liu et al. built an optimization model to solve electric vehicle charging stations [11]. The object function of his model is minimization of total cost associated with electric vehicle charging stations.

Wang et al. proposed to apply multiobjective method to plan electric vehicles charging station [12]. In their paper, they mentioned that this method could ensure charging service and reducing power losses. Finally, the well-established cross-entropy method is utilized to solve the planning problem.

From the perspective of realistic operability, Liu analysed the construction, management and standardization of battery replacement charging stations [13]. He also analysed the operability of battery replacement charging station by comparing charging time, management of battery circulation and safety. By analysing the charging conditions of electric vehicles, Fan et al. put forward the demand of charging technology to develop electric vehicles [14]. Besides, he analysed several factors that influence electric vehicles charging stations planning and came up with principled suggestions.

Under current circumstance, the batteries are charged at home or at work-place. Armstrong et al. discussed a special kind of charging station operation issue - the equipped battery switch station (BSS) [15]. The paper studied strategy issues for the BSS to buy and sell the electricity through the day-ahead market.

Zhang et al. applied Monte Carlo simulation method to get the number of full charged batteries that should be reserved in charging stations under battery swapping mode [16].

On the whole, there have more researches about the layout of charging stations. In this paper, an algorithm of route optimization of electric vehicles is designed, and a simulation model about the driving and charging based on the actual traffic conditions and the location of charging stations in Beijing is constructed. The simulation is done with the Anylogic simulation software, and the algorithm is applied to the simulation model. 


\section{ELECTRIC VEHICLES ROUTING ALGORITHM}

\subsection{Assumption}

In this paper we assume that all electric vehicles are replaced their lower batteries at charging stations directly and needn't wait to charge. All electric vehicles move in a linear routing.

When an electric vehicle starts and goes to destination, it may face one of three situations:

- This electric vehicle can reach the destination directly;

- Vehicle battery is lower and it can't go reaching the destination. It needs to move to a charging station firstly to replace lower battery;

- This electric vehicle is incapable of reaching the destination even its battery is full charged.

We discuss the policy for an electric vehicle to choose proper route under these three situations. Before discussing, we define notations as follow:

$R \quad$ - the electric vehicle's mileages range under current battery capacity;

$S$ - the distance between the origin and the destination;

$S_{1} \quad$ - the distance between the origin and the nearest charging station;

$S_{2} \quad$ - the distance between the destination and the nearest charging station;

$S_{3} \quad$ - the distance between the origin and the charging station;

$S_{4} \quad$ - the distance between the charging station and the destination;

$C(i)_{x}, C(i)_{y}$ - the coordinate of charging stations $i$;

$O_{x}, O_{y} \quad-$ the origin coordinates;

$D_{x}, D_{y} \quad-$ the destination coordinates.

Now we discuss three situations separately.

\subsection{Reaching destination directly}

If an electric vehicle can reach destination directly, it must meet the following conditions:

- Firstly, its mileage range must be greater than the distance between origin and destination, that is:

$$
R>S
$$

- Secondly, when this electric vehicle reached the destination, it may be out of its power. Under this circumstance, it will need to find a charge station near the destination to replace its lower battery. We should modify Eq. (1) as follows:

$$
R \geq S+S_{2}
$$

Eq. (2) tells us that the power of an electric vehicle must be enough to support it reach the destination and move to the nearest charge station.

This situation is shown in Fig. 1.

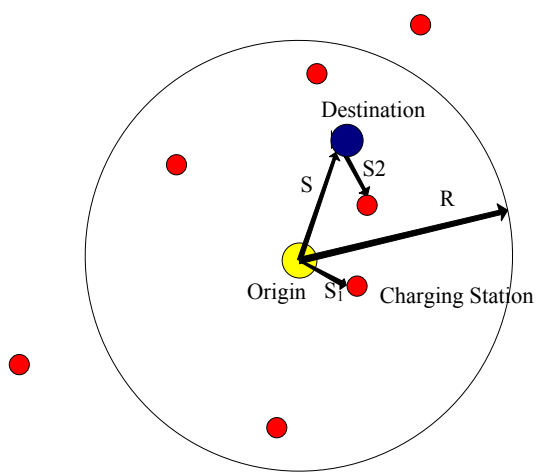

Figure 1: Situation $R \geq S+S_{2}$. 


\subsection{Before reaching destination moving to a charge station firstly}

If an electric vehicle mileage range can't meet Eq. (2), as $R<S+S_{2}$, it must find a charge station to replace its battery.

In this condition, $R$ must be greater than or equal to $S_{1}$, that is:

$$
R<S+S_{2} \text { and } R \geq S_{1}
$$

In this situation, if an electric vehicle moves to the destination, it will be out of power.

A good way to avoid trapping in this embracing situation is that this electric vehicle should find a charging station to replace the battery firstly. In this case, the routing of the electric vehicle is: origin $\rightarrow$ charge station $\rightarrow$ destination.

The travel distance is $S_{3}+S_{4}$. In order to save power, we must make this path is the shortest, that is, we must make $S_{3}+S_{4}$ minimum value. On the other hand, we must make full use of battery in electric vehicle. So we must make $S_{3}$ maximum value.

This situation is shown in Fig. 2.

We note the origin coordinate is $\left(O_{x}, O_{y}\right)$, the destination is $\left(D_{x}, D_{y}\right)$. The solver function of electric vehicle routing is obtained in Eqs. (5) to (13).

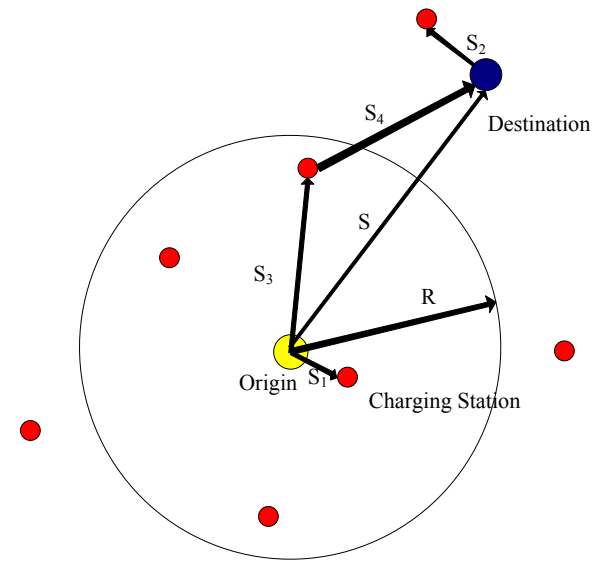

Figure 2: Situation $R<S+S_{2}$ and $R \geq S_{1}$.

Obj.:

$$
\begin{gathered}
Z_{1}=\min \left(S_{3}+S_{4}\right) \\
Z_{2}=\max \left(S_{3}\right)
\end{gathered}
$$

s.t.

$$
\begin{gathered}
S_{3}=\sqrt{\left(O_{x}-C(i)_{x}\right)^{2}+\left(O_{y}-C(i)_{y}\right)^{2}}, \quad 1 \leq i \leq n \\
S_{4}=\sqrt{\left(D_{x}-C(i)_{x}\right)^{2}+\left(D_{y}-C(i)_{y}\right)^{2}}, \quad 1 \leq i \leq n \\
S_{2}=\min \sqrt{\left(D_{x}-C(j)_{x}\right)^{2}+\left(D_{y}-C(j)_{y}\right)^{2}}, \quad j \neq i, 1 \leq j \leq n \\
S_{1}=\min \sqrt{\left(O_{x}-C(k)_{x}\right)^{2}+\left(O_{y}-C(k)_{y}\right)^{2}}, \quad k \neq i, k \neq j, 1 \leq k \leq n \\
S=\sqrt{\left(O_{x}-D_{x}\right)^{2}+\left(O_{y}-D_{y}\right)^{2}} \\
R<S+S_{2} \\
R \geq S_{1}
\end{gathered}
$$

This is a multi-objective programming problem containing two objective functions, and it could be solved by the method of linear weighted sum.

For the second objective function, Eq. (6): $Z_{2}=\max \left(S_{3}\right)$, we can change to another form:

$$
Z_{2}=\min \left(-S_{3}\right)
$$

We can combine two objective functions into one function by multiplying the first objective function with coefficient $\alpha$, and multiplying the second objective function $Z_{2}$ with 
the coefficient $(1-\alpha)$ :

$$
Z=\min \left[\alpha S_{3}+\alpha \mathrm{S}_{4}-(1-\alpha) S_{3}\right]
$$

$\alpha$ reflects the weights of the objective function $Z_{1}$ and $Z_{2}$. By simplified Eq. (15), we get:

$$
Z=\min \left[(2 \alpha-1) S_{3}+\alpha S_{4}\right]
$$

The coefficient $\alpha$ represents the trend the driver prefers to choose. If $\alpha$ is bigger, the driver thinks that to make the travel distance shorter is more important.

\subsection{Can't move to anywhere}

An electric vehicle can't move to anywhere, if it meets Eq. (17):

$$
R<S+S_{2} \text { and } R<S_{1}
$$

This situation is described in Fig. 3. In this situation, the battery is not full enough to support electric vehicle to reach the destination and any charging station. For this circumstance, the charge stations layout should be improved, and another new charge station must be constructed in this region.

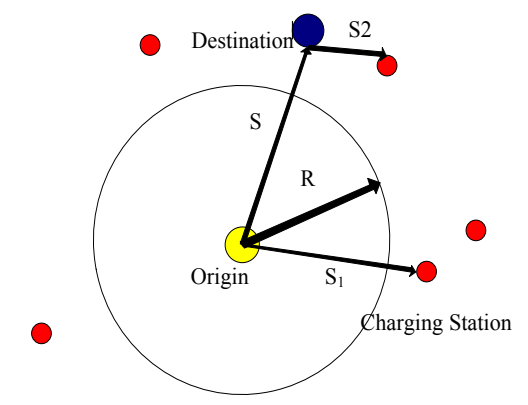

Figure 3: Situation $R<S+S_{2}$ and $R<S_{1}$.

\subsection{The mileages range for a full charged battery}

In order to make an electric car move to anywhere in a city, we must build a lot of charging stations. How much is the limited mileages range for a full charged battery? This question is related to charging stations layout in a certain area.

We assume there are $n$ charging stations in an area. The mileages range for a full charged battery is noted as $R_{f}$. If an electric car can move to a destination, it must meet the Eq. (2). That is: $R_{f} \geq S+S_{2}$.

For this circumstance, the origin is the charging station. So $S=S_{2}$. We get new inequation:

$$
R_{f} \geq 2 S_{2}
$$

We can get $R_{f}$ value by using Monte Carlo approach. The algorithm is described as follows: Step 1: We randomly generate a lot of destinations: $\mathrm{D}(1), \mathrm{D}(2), \ldots, \mathrm{D}(k), \ldots \mathrm{D}(m)$. For every destination, such as $\mathrm{D}(k)$, the coordination $D(k)_{x}$ and $D(k)_{y}$ is obeyed uniform distribution.

Step 2: Calculate $S_{2}$. We denote $l(k)$ as the distance of the $k^{\text {th }}$ destination to the nearest charging station. It is:

$$
l(k)=\min \sqrt{\left(D(k)_{x}-C(i)_{x}\right)^{2}+\left(D(k)_{y}-C(i)_{y}\right)^{2}}, \quad \forall i, 1 \leq i \leq n
$$

where $n$ is the number of charging stations.

So:

$$
S_{2}=\max \{l(1), \ldots, l(k), \ldots l(m)\}
$$

Step 3: Calculate $R_{f}$. From Eq. (18), we can get $R_{f}$. 


\section{SIMULATION MODELLING}

In this research, an Agent simulation model is built. This model contains Destination Agent, and Electric Vehicle Agent. An object of Destination Agent will randomly generate a new destination and put it into a global task queue. An object of Electric Vehicle Agent will check the task queue. If the task queue is not empty, this electric vehicle will move out a new destination from the queue. When the electric vehicle gets a new destination, it will make a decision moving to destination directly or moving to a charge station firstly.

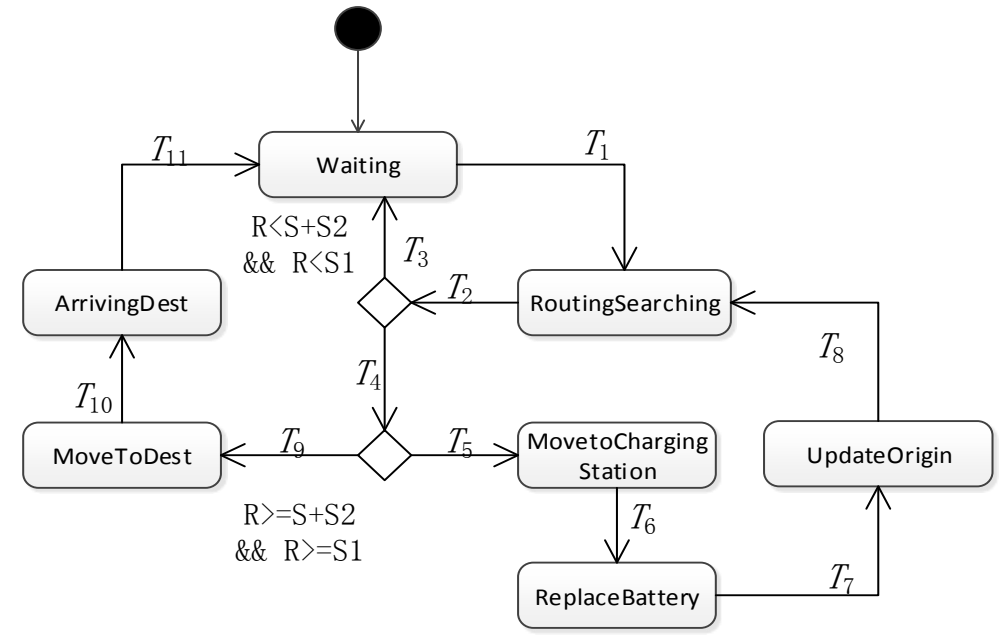

Figure 4: State chart of Electric Vehicle Agent.

The state chart of Electric Vehicle Agent is shown in Fig. 4.

In Fig. 4, electric vehicle starts in the Waiting state. If the task queue is not empty, transition $T_{1}$ will be fired and a new destination in the task queue will be moved out. The electric vehicle will enter RoutingSearching state. In this state, the variable $R, S, S_{1}, S_{2}$ will be calculated. After that, transition $T_{2}$ will be fired.

If $R<S+S_{2}$ and $R<S_{1}$, the battery capacity can't support the electric vehicle to reach the destination or any charging stations. Transition $T_{3}$ will be fired and the electric vehicle will return to Waiting state. Otherwise, $T_{4}$ will be fired.

If $R \geq S+S_{2}$ and $R>S_{1}$, the electric vehicle can reach destination directly. $T_{9}$ will be fired and electric vehicle will enter MoveToDest state. This process is easier to understand. If the electric vehicle can't meet the above condition, transition $T_{5}$ will be fired. The electric vehicle will find a charging station to replace its lower battery. It will enter the state of MoveToChargingStation and ReplaceBattery. After moving to a charging station and replacing its battery, $T_{7}$ will be fired and the electric vehicle will enter into the state of UpdateOrigin. In this state, the current location of the electric vehicle will be set as its new origin. After that, transition $T_{8}$ is fired, the electric vehicle will begin its new circulation process as before.

\subsection{The algorithm of charging station searching}

In state RoutingSearching, the electric vehicle will optimize the driving path based on algorithm mentioned in the $3^{\text {rd }}$ section.

The algorithm pseudo code is shown as follows:

Step 1: Get origin coordinates $O_{x}, O_{y}$, and destination coordinates $D_{x}, D_{y}$;

Step 2: Get electric vehicle's mileages range $R$;

Step 3: Calculate the distance $S, S_{1}, S_{2}$. Eqs. (7) to (13) show how to calculate them;

Step 4: Compare $R$ and $S+S_{2}, R$ and $S_{1}$. The pseudo code is: 
If $\left(R>=S+S_{2}\right)$ and $\left(R>=S_{1}\right)$ return 0 ;

else if $\left(R<S+S_{1}\right)$ and $\left(R<S_{1}\right)$ return -1 ;//This vehicle can't go anywhere;

else Step 5;

Step 5: Find charging station ID. Eq. (16) gives out the approach to find a charging station. It is easy to program.

\subsection{Setting simulation model parameters}

In this paper we studied the electric vehicles in Beijing. There are 13 charging stations now. These charging stations have already tested providing service for electric vehicles. The charging stations layout is shown in Fig. 5 and the coordinates are shown in Table I.

In our simulation model, the electric cars can only run in a limited area. In Beijing, the urban area is within the Fifth Ring Road and charging stations lie in this region. So this area is our simulation area. In our simulation map, the domain of $x$ coordinate is from -400 to 230 and $y$ coordinate is from 110 to 730 .

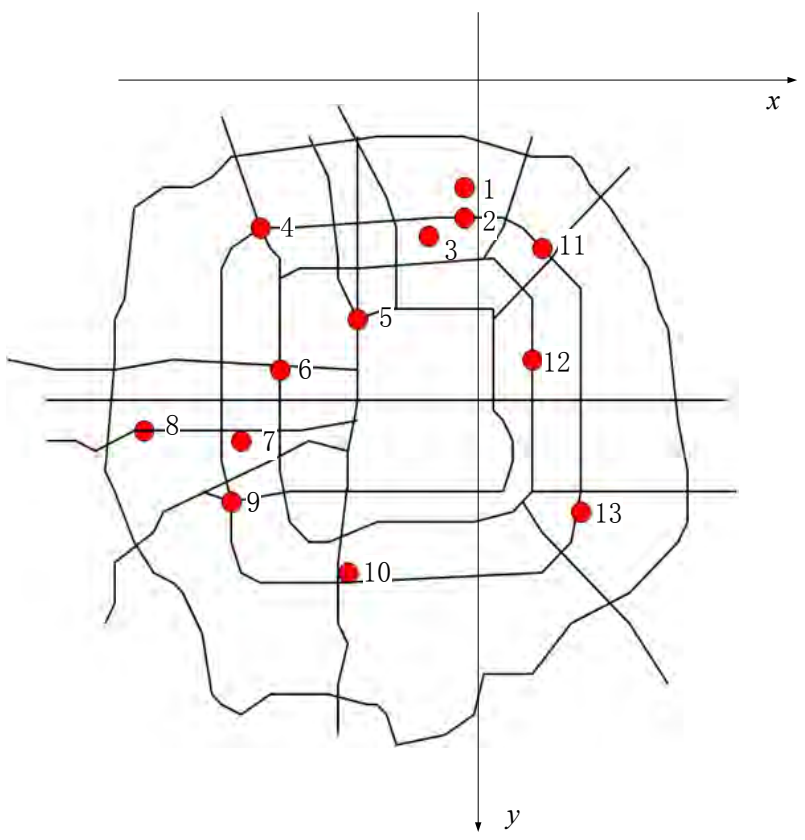

Figure 5: The layout of charging stations in Beijing (Scale $=0.046 \mathrm{~km} / \mathrm{unit}$ length).

Table I: Coordinate of charging stations in Beijing.

\begin{tabular}{|c|c|c|}
\hline Charging Station ID & Coordinate $x$ & Coordinate $y$ \\
\hline 1 & -10 & 182 \\
\hline 2 & -10 & 210 \\
\hline 3 & -47 & 228 \\
\hline 4 & -223 & 224 \\
\hline 5 & -120 & 310 \\
\hline 6 & -200 & 360 \\
\hline 7 & -240 & 430 \\
\hline 8 & -340 & 420 \\
\hline 9 & -250 & 490 \\
\hline 10 & -130 & 560 \\
\hline 11 & 70 & 240 \\
\hline 12 & 60 & 350 \\
\hline 13 & 110 & 500 \\
\hline
\end{tabular}




\subsection{The mileages range value for a full charged battery in the model}

We have discussed how to calculate $R_{f}$ in section 3. $R_{f}$ is the mileage range for a full charged battery.

If we keep $x=0$ and $y$ varies from 110 to 730 , we also can get the $R_{f}$ curve, shown in Fig. 7 .

If we keep $y=0$ and $x$ varies from -400 to 230 , we can get the curve of $R_{f}$ under this condition. It is shown in Fig. 6.

From curve $R_{f}$ in Figs. 6 and 7, we know that maximum $R_{f}$ value must come from these points: $(-400,110),(-400,730),(230,110),(230,730)$. Put these points value into Eq. (20), we can get maximum $R_{f}=566$, when $\mathrm{x}=-400, \mathrm{y}=730$. The $R_{f}$ actual distance is about $26 \mathrm{~km}$ (scale is $0.046 \mathrm{~km} / \mathrm{unit}$ length in Fig. 5).

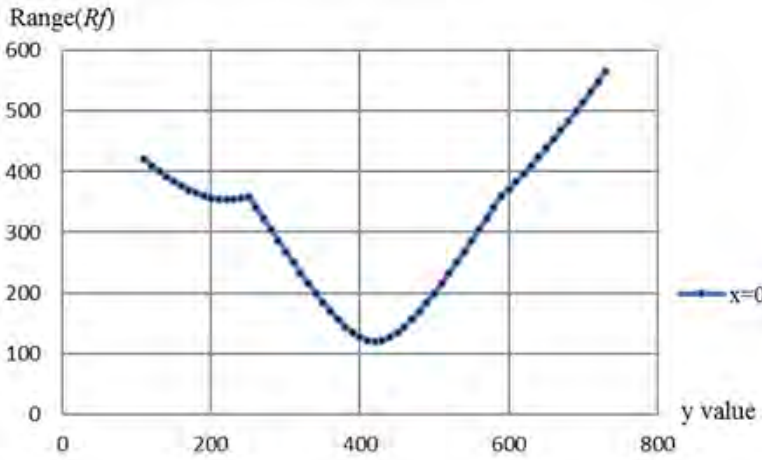

Figure 6: $R_{f}$ curve when $x=0$.

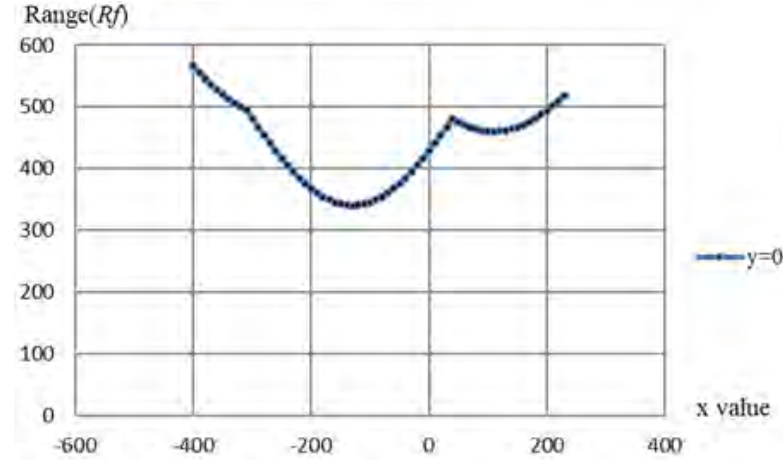

Figure 7: $R_{f}$ curve when $y=0$.

In our simulation model, the electric vehicle is running in a line without taking into account real traffic situations in Beijing. We know that, under current technology, an electric vehicle can run $80 \mathrm{~km}$ after full charged. So an electric car is capable of going to any destination, $26 \mathrm{~km}$ is gotten as electric vehicle's available distance with fully-charged battery in the simulation.

\subsection{Model validation}

We run the electric vehicle simulation model and record its trip. The parameters: $\alpha=0.75$ and $R_{f}=566$. Simulation record is shown in Table II. From Table II we can verify trip 3 whether this routing is reasonable. The routing of trip 3 is shown in Fig. 8.

Table II: Simulation record of an electric vehicle.

\begin{tabular}{|c|c|c|c|c|c|c|c|}
\hline Trip & $\begin{array}{c}\text { Initial } \\
\text { mileage } \\
\text { range }\end{array}$ & Origin $x$ & Origin $y$ & Dest. $x$ & Dest. $y$ & $\begin{array}{c}\text { Move to } \\
\text { charging } \\
\text { stations }\end{array}$ & $\begin{array}{c}\text { Remaining } \\
\text { mileage range }\end{array}$ \\
\hline 1 & 566 & 444.8 & 295.4 & -254.6 & 379.0 & 5 & 566 \\
\hline 1 & 566 & -120.0 & 310.0 & -254.6 & 379.0 & 0 & 415 \\
\hline 2 & 415 & -254.6 & 379.0 & -67.6 & 334.6 & 0 & 223 \\
\hline 3 & 223 & -67.6 & 334.6 & -77.5 & 722.4 & 5 & 566 \\
\hline 3 & 566 & -120.0 & 310.0 & -77.5 & 722.4 & 10 & 566 \\
\hline 3 & 566 & -130.0 & 560.0 & -77.5 & 722.4 & 0 & 395 \\
\hline
\end{tabular}

When the electric vehicle starts at $(-67.6,334.6)$, its mileage range is $223(R=223)$. Its battery can't support it to reach its destination (-77.5, 722.4). According to Eqs. (7) to (13) and (16), this car has to move to charging station 5 to replace its battery. After replacing its 
battery, its mileage range is reseted as $566(R=566)$. According to Eqs. (12) and (13), this car still can't move to its destination $(-77.5,722.4)$. It must find another charging station to replace second full charged battery. The solution is to move to charging station 10 according to Eqs. (7) to (13) and (16).

From Fig. 8 we know the distance of this routing is the shortest. Out simulation model and approach stand up.

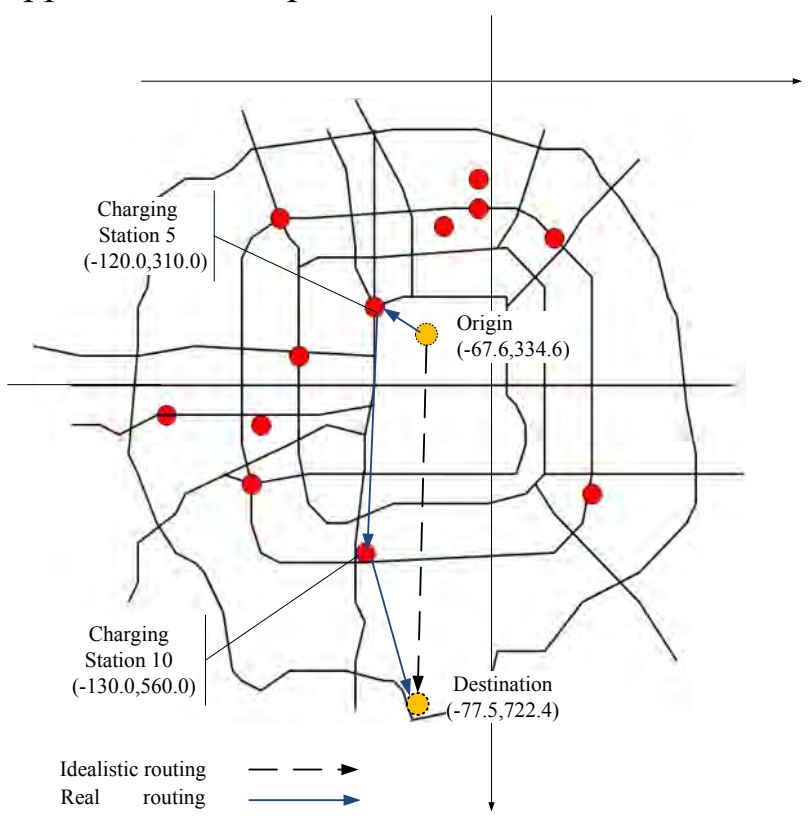

Figure 8: Routing of trip 3.

\subsection{The charging stations layout analysis}

(1) Visiting frequency

In order to analysis charging stations layout in Beijing, we set $\alpha=\{0.1,0.3,0.5,0.7,0.9\}$ and substitute it into Eq. (16). After running the simulation model, we count every charging station visiting times by electric vehicle. Table III and Fig. 9 show visiting frequency of charging stations.

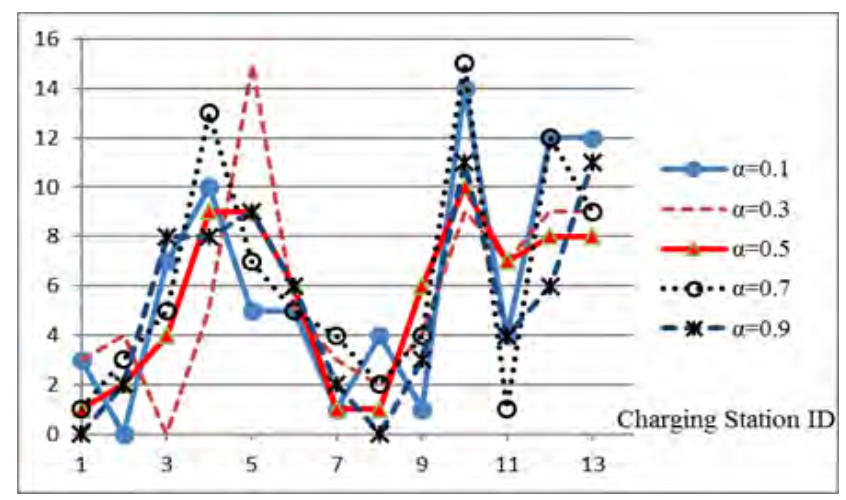

Figure 9: Charging stations visiting frequency.

From Table III we calculate mean of visiting frequency of each charging station. It is shown in Fig. 10. We find that no matter what $\alpha$ is, charging stations $4,5,10,12,13$ are in high visiting frequency. That is to say, more charging stations are needed to be built near these regions. 
Table III: Charging stations visiting frequency.

\begin{tabular}{|c|c|c|c|c|c|c|}
\hline \multirow{2}{*}{$\begin{array}{l}\text { Charging } \\
\text { Station ID }\end{array}$} & \multicolumn{5}{|c|}{ Visiting frequency } & \multirow{2}{*}{ Mean } \\
\hline & $\alpha=0.1$ & $\alpha=0.3$ & $\alpha=0.5$ & $\alpha=0.7$ & $\alpha=0.9$ & \\
\hline 1 & 3 & 3 & 1 & 1 & 0 & 1.6 \\
\hline 2 & 0 & 4 & 2 & 3 & 2 & 2.2 \\
\hline 3 & 7 & 0 & 4 & 5 & 8 & 4.8 \\
\hline 4 & 10 & 5 & 9 & 13 & 8 & 9 \\
\hline 5 & 5 & 15 & 9 & 7 & 9 & 9 \\
\hline 6 & 5 & 5 & 6 & 5 & 6 & 5.4 \\
\hline 7 & 1 & 3 & 1 & 4 & 2 & 2.2 \\
\hline 8 & 4 & 2 & 1 & 2 & 0 & 1.8 \\
\hline 9 & 1 & 4 & 6 & 4 & 3 & 3.6 \\
\hline 10 & 14 & 9 & 10 & 15 & 11 & 11.8 \\
\hline 11 & 4 & 7 & 7 & 1 & 4 & 4.6 \\
\hline 12 & 12 & 9 & 8 & 12 & 6 & 9.4 \\
\hline 13 & 12 & 9 & 8 & 9 & 11 & 9.8 \\
\hline
\end{tabular}

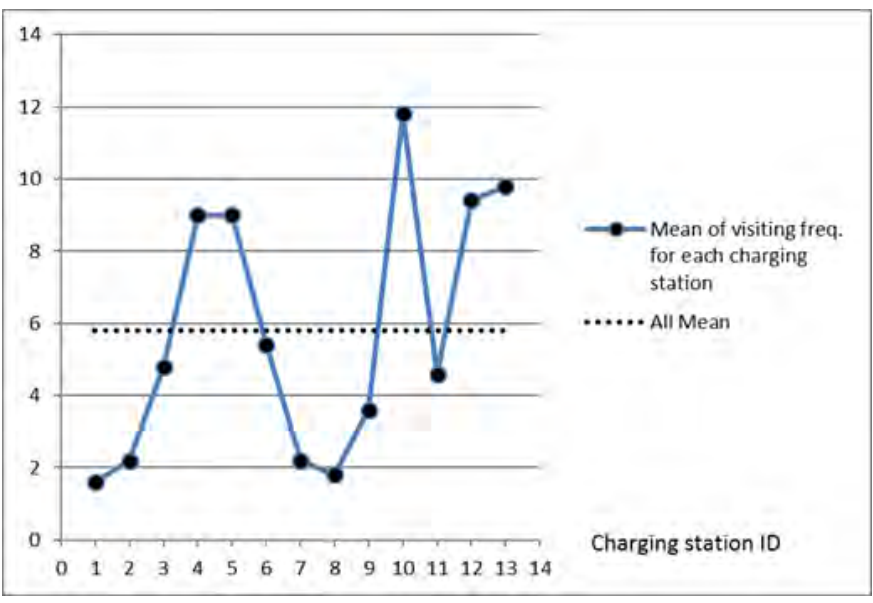

Figure 10: Mean of visiting frequency for each charging station.

(2) The hypothesis test of $\alpha$ value

In theory, with the increasing of $\alpha$, the electric vehicle detour distance will be reduced, as described in Eq. (16). But from Table III, we can't find $\alpha$ value influence on charging stations visiting frequency. So we check significance of $\alpha$ value by using Chi test.

The null hypothesis $\mathrm{H}_{0}$ is: $\mu_{1}=\mu_{2}=\ldots=\mu_{13}$

The Chi test statistics is shown in Table IV. From Table IV we know that we can't reject null hypothesis. So we think that any $\alpha$ value will not influence the simulation results.

Table IV: Chi test statistics.

\begin{tabular}{|l|c|c|c|c|c|}
\hline & $\alpha=0.1$ & $\alpha=0.3$ & $\alpha=0.5$ & $\alpha=0.7$ & $\alpha=0.9$ \\
\hline Chi-Square & $1.538^{\mathrm{a}}$ & $2.385^{\mathrm{b}}$ & $2.385^{\mathrm{b}}$ & $1.615^{\mathrm{c}}$ & $1.154^{\mathrm{b}}$ \\
\hline$d f$ & 8 & 7 & 7 & 9 & 7 \\
\hline Asymp. Sig. & 0.992 & 0.936 & 0.936 & 0.996 & 0.992 \\
\hline
\end{tabular}

Remark: for $\mathrm{a}, \mathrm{b}$, c see the comments on the next page. 
a: 9 cells $(100.0 \%)$ have expected frequencies less than 5 . The minimum expected cell frequency is 1.4 . b: 8 cells $(100.0 \%)$ have expected frequencies less than 5 . The minimum expected cell frequency is 1.6. c: 10 cells $(100.0 \%)$ have expected frequencies less than 5 . The minimum expected cell frequency is 1.3 .

\section{CONCLUSIONS}

This paper discussed a routing optimizing algorithm for an electric vehicle searching charging station. In the paper, the specific road conditions and traffic problems are not taken into account. Part of data may be modified if an electric vehicle is driven along city real roads.

By applying routing optimization method, we have built a simulation model and applied it to Beijing's charging stations to verify the algorithm. The results show that our approach is valid.

We have found that the minimum mileage range of a full charged electric vehicle in Beijing is about $26 \mathrm{~km}$. If an electric vehicle runs in linear routing, all electric vehicles' batteries could reach $26 \mathrm{~km}$ easily. The charging stations could support electric vehicles run very well in Beijing.

We also have studied the charging stations layout in Beijing. We have found the layout is not reasonable, in some areas too densely located while some other areas are too thin. With the popularity of electric cars, unreasonable charging stations layout will not be able to meet the requirements of electric vehicles and hinder the development of the electric cars.

\section{ACKNOWLEDGEMENT}

This paper is funded by National Natural Science Foundation of China (Grant No. 71132008) and the Lab of Logistics Management and Technology.

\section{REFERENCES}

[1] Gong, H.; Wang, M. Q.; Wang, H. (2013). New energy vehicles in China: Policies, demonstration and progress, Mitigation and Adaptation Strategies for Global Change, Vol. 18, No. 2, 207-228, doi:10.1007/s11027-012-9358-6

[2] Zhang, W.; Wu, B.; Li, W.; Lai, X. (2009). Discussion on development trend of battery electric vehicles in China and its energy supply mode, Power System Technology, Vol. 33, No. 4, 1-5

[3] Raviv, T. (2012). The battery switching station scheduling problem, Operations Research Letters, Vol. 40, No. 6, 546-550, doi:10.1016/j.orl.2012.09.007

[4] Hiwatari, R.; Ikeya, T.; Okano, K. (2011). A road traffic simulator to analyze layout and effectiveness of rapid charging infrastructure for electric vehicle, Vehicle Power and Propulsion Conference (VPPC), Chicago, 1-6

[5] Yao, M.; Liu, H.; Feng, X. (2011). The development of low-carbon vehicles in China, Energy Policy, Vol. 39, No. 9, 5457-5464, doi:10.1016/j.enpol.2011.05.017

[6] Zhou, F. Q.; Lian, Z. W.; Wang, X. L. (2010). Discussion on operation mode to the electric vehicle charging station, Power System Protection and Control, Vol. 38, No. 21, 63-67

[7] Yilmaz, M.; Krein, P. T. (2013). Review of battery charger topologies, charging power levels, and infrastructure for plug-in electric and hybrid vehicles, IEEE Transactions on Power Electronics, Vol. 28, No. 5, 2151-2169, doi:10.1109/TPEL.2012.2212917

[8] Guo, K. (2011). Consideration of the industrialization of electric vehicles in China, China Engineering Science, Vol. 13, No. 9, 4-7

[9] Liu, J. (2012). Electric vehicle charging infrastructure assignment and power grid impacts assessment in Beijing, Energy Policy, Vol. 51, 544-557, doi:10.1016/j.enpol.2012.08.074

[10] Liu, Z. P. (2012). Optimal location and capacity of electric vehicle charging stations, Automation of Electric Power Systems, Vol. 36, No. 3, 54-59 
[11] Liu, Z.; Wen, F.; Ledwich, G. (2013). Optimal planning of electric-vehicle charging stations in distribution systems, IEEE Transactions on Power Delivery, Vol. 28, No. 1, 102-110, doi:10.1109/TPWRD.2012.2223489

[12] Wang, G.; Xu, Z.; Wen, F.; Wong, K. P. (2013). Traffic-constrained multiobjective planning of electric-vehicle charging stations, IEEE Transactions on Power Delivery, Vol. 28, No. 4, 2363 2372, doi:10.1109/TPWRD.2013.2269142

[13] Liu, J. X. (2010). Operability analysis of electric cars battery replacement charging station construction, Science Mosaic, Vol. 3, 26-29

[14] Fan, X.; Guoqin, Y.; Linfeng, G. (2009). Tentative analysis of layout of electrical vehicle charging stations, East China Electric Power, Vol. 37, No. 10, 1678-1682

[15] Armstrong, M.; El Hajj Moussa, C.; Adnot, J.; Galli, A.; Riviere, P. (2013). Optimal recharging strategy for battery-switch stations for electric vehicles in France, Energy Policy, Vol. 60, 569582, doi:10.1016/j.enpol.2013.05.089

[16] Zhang, C.; Meng, J.; Cao, Y.; Huang, Q.; Jing, S.; Liu, Q. (2012). A battery swapping requirement adequacy model for electric vehicles and its simulation research, Power System Technology, Vol. 36, No. 9, 15-19 